\title{
Understanding the negative thermal expansion in planar graphite-metal composites
}

\author{
Valerio Oddone ${ }^{1}$, Robert C. Wimpory ${ }^{2}$, Stephanie Reich ${ }^{1}$ \\ Corresponding author: Valerio Oddone, valerio.oddone@ gmail.com, 00493083854294 \\ ${ }^{1}$ Freie Universität Berlin, Arnimallee 14, 14195 Berlin, Germany \\ ${ }^{2}$ Helmholtz-Zentrum Berlin für Materialien und Energie, Hahn-Meitner-Platz 1, 14109 \\ Berlin, Germany
}

The addition of graphitic fibers and flakes as fillers is commonly used to control the thermal expansion of metals. Sintered metal matrix composites with a planar distribution of graphite flakes show a low or negative thermal expansion coefficient perpendicular to the orientation plane of the graphite (z-CTE). Since the metal matrix has a positive isotropic expansion and graphite has a high z-CTE, this effect cannot be explained by a simple model of stapled metalgraphite layers. Instead, a mechanical interaction between graphite and matrix must be considered. With neutron scattering measurements we show that there is little or no strain of the graphite flakes caused by the matrix, which can be explained by the high modulus of graphite. Instead, we suggest that a macroscopic crumpling of the flakes is responsible for the low z-CTE of the composite. The crumpled flakes are thicker at low temperature and get stretched and flattened by the expanding matrix at high temperature, explaining the reduction in the thermal expansion across the orientation plane.

Keywords: thermal expansion, anisotropy, graphite, composite, powder metallurgy, spark plasma sintering

\section{Introduction}

A mismatch in the coefficient of thermal expansion (CTE) is a serious issue for systems working under temperature fluctuations such as heat sinks[1,2] or high performance engines, in which components made of different metals or even ceramics are mechanically connected. If the different thermal expansion is not absorbed by flexible components, the induced stress will weaken the structure and may cause failure. Carbon based particles and fibers are widely used as filler in metal matrices for reducing the CTE[3, 4, 13, 5-12]. Carbon fibers and carbon nanotubes have a low or negative CTE along the fiber direction, graphene and graphite flakes along the crystal lattice plane. For niche applications, even synthetic diamond particles 
are used[9], which have a low CTE in all three directions. These properties are partially transferred to the composite.

Metals normally have an isotropic CTE. Crystalline graphite flakes show low in-plane (x,y) CTE and high through-plane (z) CTE. Remarkably, for sintered graphite metal composites with a planar distribution of the graphite flakes, the opposite behavior was observed. The composites have a high $\mathrm{x}, \mathrm{y}-\mathrm{CTE}$ and low or even negative z-CTE, which cannot be explained by the rule of mixtures of the components considering the different elasticity moduli. The effect was reported previously for copper-graphite composites[10, 14] and for composites with aluminum and magnesium alloys as matrix, for various graphite powders and production parameters[11]. The same results for copper-graphite composites were later perfectly reproduced by Chu et al[15] on nearly identical samples, whereby the CTE was measured by SEM instead of dilatometry, and attributed to a strain of the graphite flakes which will be discussed below. A similar effect was reported by Hutsch et al[16] for composites with tungsten matrices and above $70^{\circ} \mathrm{C}$ for copper matrices, later for iron matrices[17]. Hutsch attributed the effect in iron-graphite composites to the formation of grain-boundary cementite during sintering. Zhou et al[18] measured slightly lower z-CTE than $\mathrm{x}, \mathrm{y}-\mathrm{CTE}$ in ternary composites of aluminum alloy, silicon particles and graphite flakes (up to 200-300 $\mu \mathrm{m}$ in diameter). On the other hand, Rawal[6] reported a strong CTE reduction on the $\mathrm{x}, \mathrm{y}$-plane, as in pure graphite, for composites produced by diffusion bonding and Prieto et al[13] for composites produced by metal infiltration and with a filler composition of $90 \%$ graphite and $10 \%$ carbon fibers. The fiber content indeed reduces the $\mathrm{x}, \mathrm{y}-\mathrm{CTE}$ and increases the z-CTE. However, we still observed lower z-CTE than x,y-CTE for filler mixtures with up to $25 \%$ carbon fibers[19]. Pure carbon fibers as filler resulted in higher z-CTE and lower x,yCTE[12].

A theoretical modeling of the CTE for the described composites is not trivial. Wang et al[20] made a review of common methods to model the CTE of metal matrix composites, which were than compared for copper-graphene composites: The Schapery model[21], Kerner's model[22], Turner's model[23] and McCullough's model (or Rule of Mixture model)[24]. These four models are not suited for materials combining anisotropic fillers with high aspect ratio and a strong interaction with the matrix. Zhou et al[18] explicitly stated not being able to fit the CTE of this kind of graphite-metal composites with any of these four models.

In this paper we discuss in detail the thermal expansion of sintered metal matrix composites with a planar distribution of graphite flakes in view of the models to describe the observed 
behavior. The reduced z-CTE was previously explained by a strain of the graphite flakes induced by the metal matrix. By neutron scattering measurements we show that no such strain is present in the filler material. Instead, we propose a macroscopic stretch of folded graphite flakes as the origin of the anomalous CTE.

\section{Materials and methods}

Metal matrix composites with large graphite flakes as filler were produced by spark plasma sintering (SPS). The characterization was performed by dilatometry and neutron scattering.

A mixture of metal powder and large graphite flakes (approx. $10 \mu \mathrm{m} \times 500 \mu \mathrm{m}, N G S$ Naturgraphit, Germany) was prepared by manual mixing. The matrix to filler ratio is 1:1 in volume, unless stated otherwise. The following metal powders were used: pure copper ( $3 \mu \mathrm{m}$, Sigma Aldrich), aluminum alloys (A17075 and A12024, $25 \mu \mathrm{m}$, Ecka Granules, Germany), a magnesium alloy (mechanically alloyed Mg-0.9Ca, Helmoltz-Zentrum Geesthacht, Germany) and the metal mixture AM431 (Alumix 431, Al-1.5Cu-2.5Mg-5.5Zn, $60 \mu \mathrm{m}$, Ecka Granules, Germany).

Sintering was performed by SPS in a Dr. SinterLab Jr. 211Lx. Cylindrical samples with a diameter of $6 \mathrm{~mm}$ and a height of 4-5 $\mathrm{mm}$ were produced in graphite crucibles with a unidirectional pressure of $50 \mathrm{MPa}$. The heating rate was set to $100 \mathrm{~K} \mathrm{~min}^{-1}$ up to $100 \mathrm{~K}$ below the maximal temperature, followed by $50 \mathrm{~K} \mathrm{~min}^{-1}$ to the maximal temperature. The maximal temperature was $600^{\circ} \mathrm{C}$ for copper, $550^{\circ} \mathrm{C}$ for $\mathrm{Al} 2024$ and $\mathrm{Mg}-0.9 \mathrm{Ca}, 500^{\circ} \mathrm{C}$ for $\mathrm{Al} 7075$ and AM431; it was held for 4 minutes. The heating was performed in a vacuum of $1 \mathrm{~Pa}$. We did not observe significant variations in the results when increasing the holding times, or reducing the sintering temperature, heating rates, and pressure.

The unidirectional pressure of the SPS process orients the graphite flakes on a plane perpendicular to the pressure, as visible in Figure 1. 


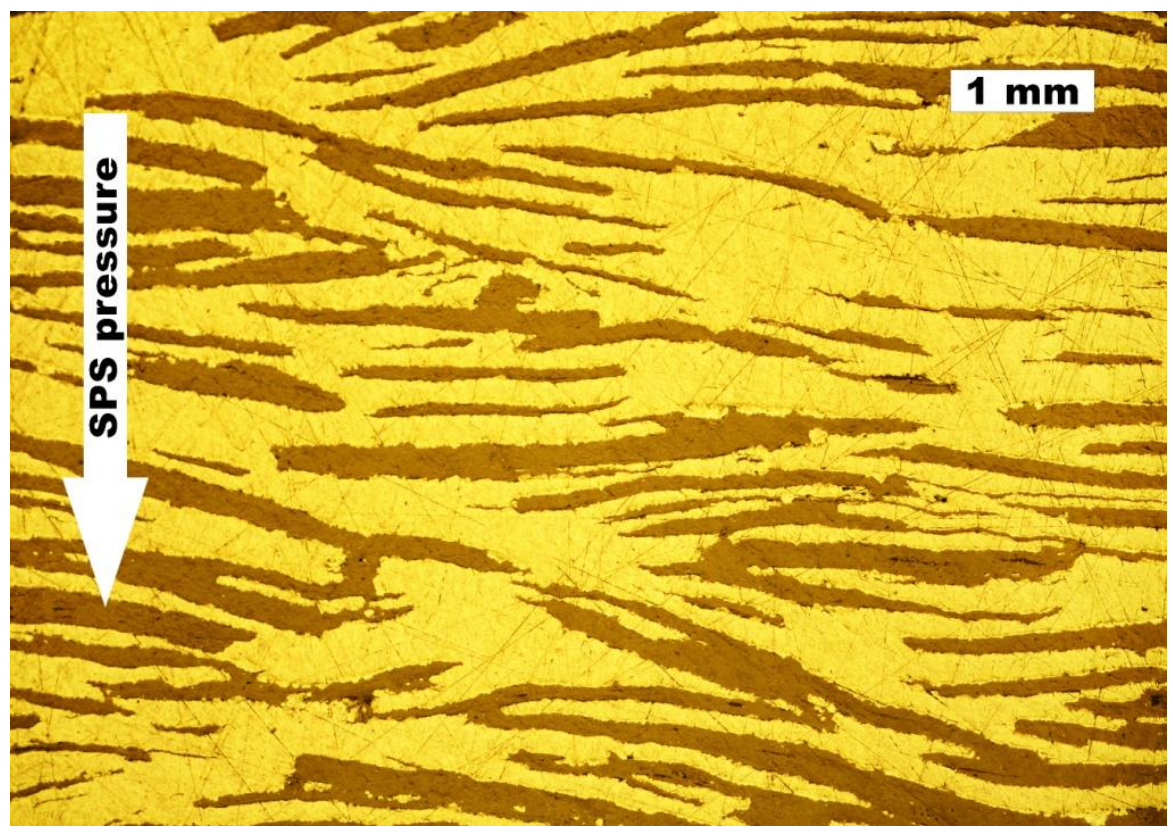

Fig. 1 Optical micrograph of a graphite composite parallel to the pressing axis (z-direction). The orientation of the graphite flakes (dark) on the $\mathrm{x}, \mathrm{y}$-plane is clearly visible.

Most samples received a T6 thermal treatment prior to the measurements, i.e. $2 \mathrm{~h}$ solution heat treatment, quenching in cold water, and $18 \mathrm{~h}$ artificial aging. For Al7075 and AM431 the heat treatment was performed at $450^{\circ} \mathrm{C}$, aging at $160^{\circ} \mathrm{C}$; for $\mathrm{A} 12024$, respectively, $470^{\circ} \mathrm{C}$ and $190^{\circ} \mathrm{C}$. Samples of $\mathrm{Mg}-0.9 \mathrm{Ca}$ were annealed for $2 \mathrm{~h}$ at $350^{\circ} \mathrm{C}$. Copper samples were not treated.

Measurements were also performed on samples produced for previous studies $[11,14]$. They include various additional metal powders, such as pure copper, pure aluminum and pure magnesium, aluminum and magnesium alloys (in particular the Al-Si powder mixture AM231), as well as different graphite flakes, varying the metal to graphite ratios, alternating powder mixture preparations and sintering parameters. These samples will be clearly indicated; their production details are available in the references.

Thermal expansion measurements were performed by dilatometry with a Linseis L75XH100O. Between three and ten cycles from $35^{\circ} \mathrm{C}$ and $155^{\circ} \mathrm{C}$ were performed with heating/cooling rates of up to $1 \mathrm{~K} \mathrm{~min}^{-1}$ (some materials needed more cycles before showing a stable behavior after sintering. See also Fig. 2). This temperature range is sufficient for the envisioned application of the material as heat sinks. The average physical CTE between $90^{\circ} \mathrm{C}$ and $110^{\circ} \mathrm{C}$ was used for the evaluation, since it is least affected by hysteresis that was in part caused by the measuring technique. Selected samples were tested up to $350^{\circ} \mathrm{C}$ for a better understanding of the physical mechanism behind the anomalous CTE. 
Neutron scattering was used for determining thermal strain and expansion in the graphite flakes several millimeters below the surface of the composite. The measurements were performed at the Helmoltz-Zentrum Berlin for Materials and Energy, using the neutron source BER II and the experimental setup E3, Residual Stress Analysis and Texture Diffractometer. The neutron wavelength was $0.147 \mathrm{~nm}(38 \mathrm{meV})$.

The lattice parameters of the graphite flakes were measured in various metal matrices between $50^{\circ} \mathrm{C}$ and $150^{\circ} \mathrm{C}$. We measured the thermal expansion of the graphite flakes inside and outside the composite to investigate the strains induced by the metal matrix. Measurements of the 006 diffraction peak were used to determine the z-strain, while measurements of the 105 and 112 peaks were used to investigate strains in the $\mathrm{x}, \mathrm{y}$-plane.

\section{Results and discussion}

We evaluated the CTE of metal matrix composites with a planar distribution of graphite flakes. To ensure that the observed behavior is generally found in graphite-metal composites, a great variety of matrices was considered. Crystalline graphite has a $\mathrm{x}, \mathrm{y}-\mathrm{CTE}$ of $-1 \mathrm{ppm} \mathrm{K} \mathrm{K}^{-1}$ (in-plane) and z-CTE of $28 \mathrm{ppm} \mathrm{K}^{-1}$ (through-plane)[25]. The metals used have a CTE between $17 \mathrm{ppm} \mathrm{K}^{-1}$ for copper and over $25 \mathrm{ppm} \mathrm{K}^{-1}$ for magnesium alloys. For all composites, the measured CTE is low or even negative $\left(-10 \mathrm{ppm} \mathrm{K}^{-1}\right)$ along the $\mathrm{z}$-axis and around 15 ppm $\mathrm{K}^{-1}$ in the $\mathrm{x}, \mathrm{y}$-plane. This is geometrically opposite to the properties of the graphite filler (Table 1). Aluminum alloys matrices have lead to a negative z-CTE. It persists up to 150$200^{\circ} \mathrm{C}$ and slowly shifts to positive values for higher temperatures. For lower graphite concentration, the CTE decreases linearly from the value of the pure matrix to the values of the 1:1 composite; higher graphite concentrations are difficult to achieve due to the mechanical instability of the obtained composites[11].

The lowest z-CTE of the composites is achieved for metal matrices with high CTE, especially for the aluminum alloys. For matrices with higher elasticity modulus (aluminum alloys A12024, Al7075 and AM431) we observe lower z-CTE in the composite. Samples produced with the high strength aluminum alloy A17075 have a much lower z-CTE than samples with the soft pure aluminum and magnesium alloy matrix. Both effects suggest that the matrix produces strain in the graphite flakes.

Table 1 In the top lines of the tables, the experimental CTE $\left(\mathrm{ppm} \mathrm{K}^{-1}\right)$ of sintered metals and composites with 1:1 metal to graphite concentration are reported (data from Firkowska et al. for Copper[14] and from our previous study[11]). In the bottom part of the table, for a given $\mathrm{x}, \mathrm{y}-\mathrm{CTE}$ of 
the composite (experimental value), the Poisson's ratio was used to calculate the z-CTE of the compressively strained matrix and Firkowska's theory was used to predict the z-CTE of the stretched matrix [14]. For a 1:1 volumetric ratio of metal and graphite, the sum of matrix and filler gave the theoretical z-CTE of the composite.

\begin{tabular}{c|cccccccc}
\hline \hline Material & $\mathrm{Cu}$ & $\mathrm{Al}$ & $\mathrm{Al2024}$ & $\mathrm{Al7075}$ & $\mathrm{AM} 331$ & AM231 & Mg-0.9Ca & AZ31 \\
\hline Matrix CTE & 17 & 23.5 & 24.7 & 24.1 & 24.4 & 18.5 & 25.8 & 25.8 \\
Composite x,y-CTE & 12 & 19.6 & 16.6 & 17.5 & 20.2 & 10.9 & 17.6 & 17.5 \\
Composite z-CTE & 2 & 10 & -7.3 & -9.2 & -4.2 & -2.9 & 2.1 & 2.5 \\
\hline Poisson's ratio (matrix) & 0.33 & 0.32 & 0.32 & 0.32 & 0.32 & 0.32 & 0.28 & 0.28 \\
Strained matrix z-CTE (th) & 24 & 28 & 35 & 33 & 30 & 28 & 35 & 35 \\
Strained graphite z-CTE (th) & -26 & -32 & -30 & -30 & -33 & -25 & -30 & -30 \\
Composite z-CTE (th) & -2 & -4 & 5 & 3 & -3 & 3 & 5 & 5 \\
\hline \hline
\end{tabular}

Hutsch et al suggested the formation of cementite during sintering, i.e. an intermetallic compound of iron and carbon [17]. We exclude a similar effect for our aluminum matrix. In a previous work [19] we showed that the carbide formation at the interface between graphite and metal is not significant and increases for higher sinter temperatures. The CTE instead is independent of the sinter temperature. The large number of examined metal matrices excludes such explanations that depend on the specific material constitution. Instead, we considered mechanical models to explain the anomalous expansion.

Firkowska et al [14] explained the anomalous CTE with a layer model assuming that the graphite flakes are compressed in the $\mathrm{x}, \mathrm{y}$-plane during the cooling process after the SPS. When the composite is heated, the expanding metal matrix allows a relaxation of the graphite flakes in the $\mathrm{x}, \mathrm{y}$-plane, which consequently shrink along the $\mathrm{z}$-axis, explaining the low $\mathrm{z}$-CTE of the composite. The residual strain is assumed to be zero at approximately $400^{\circ} \mathrm{C}$ for copper samples and increases for lower temperatures. The negative CTE along the z-axis is determined by the Poisson ratio of graphite and its temperature dependence [14]. Additionally, the model uses the measured x,y-CTE of the composite, the elastic constants and temperature derivatives for matrix and graphite. The layer model correctly predicted the measured z-CTE for composites with a copper matrix [14]. Chu et al [15] observed in later experiments the same phenomenon. They were able to predict the CTEs using Firkowska's model [14] as well as Turner's [23] and Kerner's [22] model. All calculations assumed a strong strain of the graphite flakes in the copper matrix. 
We now apply the theory to composites with light metal matrices. We assume the residual strain to be zero at $200^{\circ} \mathrm{C}$, since above this temperature the reduction in z-CTE gradually disappears. Since the light metal matrix has a higher CTE than copper, the residual strain $\varepsilon_{11}$ in the $\mathrm{x}, \mathrm{y}$-plane at room temperature is on the same order of magnitude as in copper, $\varepsilon_{11} \approx 10^{-}$ ${ }^{3}$. As an example, we evaluate the model for AM431 composites. With the $\mathrm{x}, \mathrm{y}-\mathrm{CTE}$ of $20.2 \mathrm{ppm} \mathrm{K}^{-1}$ in the composite, a z-CTE of $\approx-33 \mathrm{ppm} \mathrm{K}^{-1}$ for the graphite flakes is obtained. The reduced $\mathrm{x}, \mathrm{y}-\mathrm{CTE}$ of the AM431 in the composite $\left(20.2 \mathrm{ppm} \mathrm{K}^{-1}\right)$ increases the $\mathrm{z}$-CTE due to the Poisson's effect (Poisson's ratio of 0.33 ) to $29.8 \mathrm{ppm} \mathrm{K}^{-1}$. A composite of 1:1 AM431 to graphite ratio has a predicted $\mathrm{z}-\mathrm{CTE}$ of $\approx-3 \mathrm{ppm} \mathrm{K}^{-1}$, which is near to the measured value of $-4.2 \mathrm{ppm} \mathrm{K} \mathrm{K}^{-1}$. As showed in Table 1, the difference between theory and experiment is higher for other metals, but the model still gives a qualitative description of the reduced zCTE.

The mechanical layer model correctly predicts a reduction in z-CTE. However its physical description is not applicable for composites with metal matrices that are weaker than the $\mathrm{sp}^{2}$ carbon filler. The elasticity modulus of crystalline graphite in the $\mathrm{x}, \mathrm{y}$ planes exceeds by over one order of magnitude the elasticity modulus of the metal matrices (> TPa in graphite[26], $117 \mathrm{GPa}$ in copper, 60-80 GPa in aluminum alloys [27, 28] and 40-46 GPa in magnesium alloys[29]). In a composite with a 1:1 volumetric composition of graphite and metal, a thermal strain in graphite due to the action of the matrix appears unlikely.

We examined the prediction of the layer model on a microscopic scale by neutron scattering measurements.

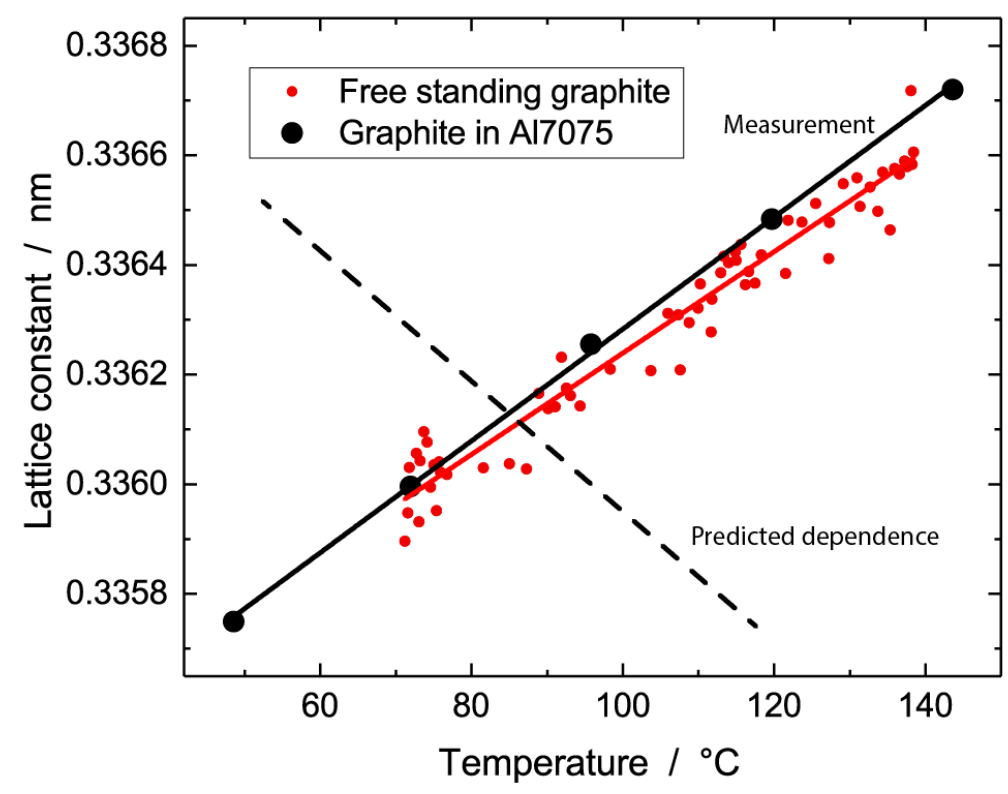


Fig. 2 Lattice constant in z-direction for free graphite flakes and for graphite flakes embedded in an aluminum alloy Al7075 matrix as a function of temperature. The concordance of the data shows the absence of significant thermal strain and residual strain in the embedded graphite flakes. The dashed line shows the predicted temperature dependence of the lattice constant of embedded graphite flakes according to Ref. [14] (-30 ppm K ${ }^{-1}$ for Al7075 matrix, see Table 1).

In Fig. 2 the lattice constant of free graphite flakes and for flakes embedded in an A17075 matrix are plotted as a function of temperature. The negative z-CTE of the investigated composite $\left(-9 \mathrm{ppm} \mathrm{K}^{-1}\right)$ was verified before and after neutron scattering. The excellent agreement between the c-axis lattice constant at low temperatures for free graphite and graphite embedded in the AL7075 matrix demonstrates the absence of residual strain after the sintering process. The slope of free-standing graphite and the graphite filler in the composite are almost identical showing that the expanding matrix has no effect on the size of the graphite flakes. The model of Ref. [14] predicted a residual strain for the graphite filler on the order of $\approx 10^{-3}$ at room temperature, i.e. a shift of the lattice constant of $0.3 \mathrm{pm}$ above the unstrained graphite, and a negative expansion in z-direction, i.e. a negative slope in Fig. 2 (dashed line). For the other matrices, the z-CTE of the graphite flakes from neutron scattering are summarized in Table 2. We measure for the graphite in all composites z-CTE of $29 \pm 2 \mathrm{ppm} \mathrm{K}^{-1}$ and for the free standing graphite $27.5 \mathrm{ppm} \mathrm{K}^{-1}$. The strain in graphite fillers is minimal and their z-CTE remains large and positive in contrast to the layer model that predicted negative z-CTE for graphite fillers in the metal (Table 1, Strained graphite z-CTE). Similarly, these results do not agree with the assumption in Chu's model that the average CTE of embedded graphite is $-4.6 \mathrm{ppm} \mathrm{K}^{-1}[15]$.

Table 2 z-CTE (ppm K ${ }^{-1}$ ) of free standing graphite and the graphite flakes under strain in different composites as measured by neutron scattering.

\begin{tabular}{lllllllll}
\hline \hline \multirow{2}{*}{ Matrix } & Copper & $\begin{array}{l}\text { Al7075, } \\
\text { sample 1 }\end{array}$ & $\begin{array}{l}\text { Al7075, } \\
\text { sample 2 }\end{array}$ & Al2024 & $\begin{array}{l}\text { AM431*, AM431*, Mg- } \\
\text { sample 1 }\end{array}$ & $\begin{array}{l}\text { Pure } \\
\text { sample 2 }\end{array}$ & $\begin{array}{l}\text { 0.9Ca } \\
\text { graphite }\end{array}$ \\
\hline Gr. z-CTE & 27 & 29 & 30 & 31 & 31 & 29 & 29 & 27.5 \\
\hline \hline
\end{tabular}

Although the mechanical layer model fails on a microscopic level, it obviously captures part of the underlying mechanism. We suggest that it is correct on a macroscopic scale: the graphite crystal lattice is not strained microscopically since the elasticity modulus is too high. However, the thin flakes are macroscopically crumpled in the $\mathrm{x}, \mathrm{y}$-plane by the cooling matrix 
after sintering. This causes an effective expansion in the z-direction. When the composite is heated, the expanding matrix stretches the flakes along the $\mathrm{x}, \mathrm{y}$-plane, removing the folds and reducing the z-thickness of the graphite flakes. Due to the layered structure (Fig. 1), the thickness of the graphite flakes can change with little or no strain in the metal matrix. For a given shrinkage of the matrix in the $x, y$-plane, the increase in thickness of a graphite flake depends on the periodicity of the crumpling, the orientation and the overlap of the graphite flakes (Fig. 3). High bending stiffness of the flakes and poor adhesion between matrix and graphite may cause large folds, with a consequently higher thickness increase. A poor adhesion between graphite layers in contact may additionally cause a disordered superposition of the layers, with inner porosity and larger thickness increase. Knowledge of these two parameters is necessary for quantitative predictions of the z-CTE of the composite. Neutron scattering may be used to measure the temperature dependent orientation of the graphite in the matrix. Such experiments would be a qualitative proof of the macroscopic model and highly desirable.

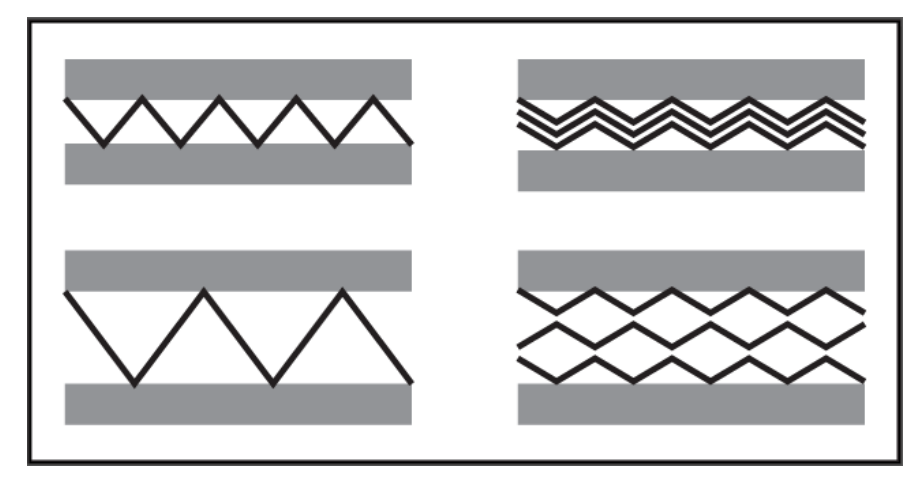

Fig. 3 The geometry and distribution of the crumpled graphite flakes in the metal matrix. For a given strain of the matrix in the x,y-plane, both the length of the folds (left) and the superposition of the layers (right) have a significant influence on the z-CTE of the composite.

As an additional experiment we studied the evolution of the CTE after sintering. The first dilatometry curves for a composite with Al2024 matrix is shown in Fig. 4. The x,y and z expansion curves were acquired directly after SPS without thermal treatments or other thermal cycles. Similar pictures are observed for the other composites. Samples with low zCTE show a strong hysteresis in the z-axis dilatometry. Briche et al[30] suggest that the hysteresis is a consequence of reversible damages caused by the CTE mismatch in the composite. Moreover, for all samples measured directly after sintering, i.e. before a thermal treatment, we observe a net expansion in z-direction during the first heating and cooling cycles that asymptotically reaches a maximum after tens of cycles. During the first heating 
phase, the z-CTE is always higher than after 2-3 cycles or after a thermal treatment at higher temperature, where a stable behavior is achieved. Apparently, empty space is created around the graphite flakes, which is supported by a $5-10 \%$ reduction in the thermal conductivity of the composite after a thermal treatment[11].

A second aspect is that the material shrinks in z-direction only up to a maximal temperature. For dilatometry measurements to higher temperatures, we observed a minimum in the relative length change at $150-220^{\circ} \mathrm{C}$, depending on the material and on the maximal temperature of the cycle. In particular, the composite with A12024 matrix showed in Fig. 4 reached in cycles between $50^{\circ} \mathrm{C}$ and $350^{\circ} \mathrm{C}$ the minimal z-expansion at $210^{\circ} \mathrm{C}$ and had a positive z-CTE of $15 \mathrm{ppm} \mathrm{K}^{-1}$ at $350^{\circ} \mathrm{C}$. Above $220^{\circ} \mathrm{C}$ all measured materials had a positive $\mathrm{z}$-CTE. This observation supports the proposed theory of crumpling graphite flakes. At a particular temperature the expanding matrix completely unfolds the graphite flakes, which reach its minimal thickness. Above this temperature the composite behaves like a staple of graphite and metal, i.e. with positive z-CTE.

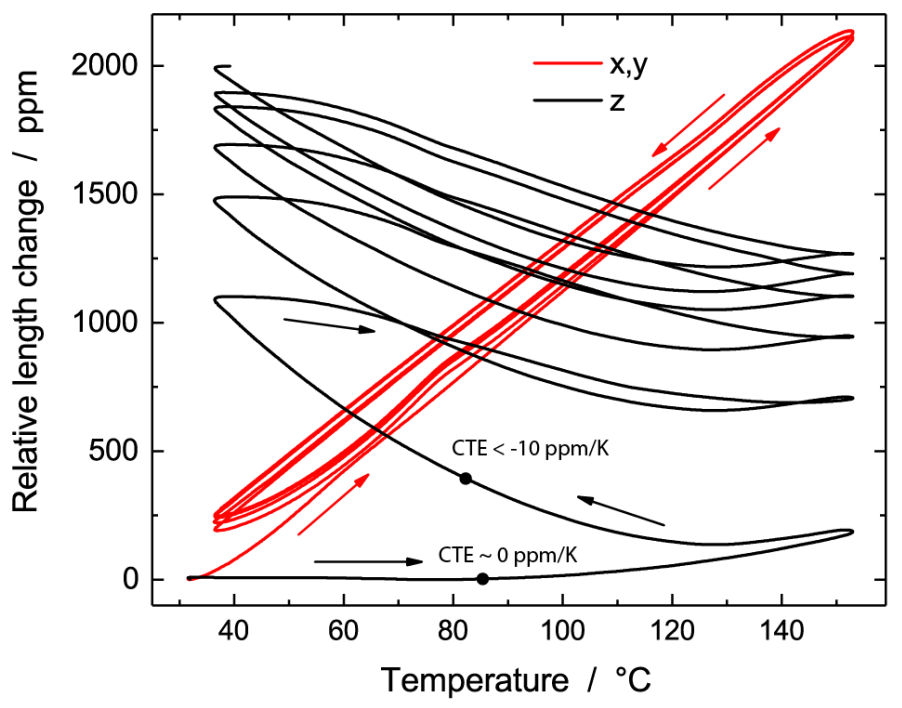

Fig. 4 Dilatometry curves of an AL2024 composite in the x,y-plane (red) and in z-direction (black). The progressive expansion and hysteresis in z-direction is evident. During the first heating curve, the $\mathrm{z}-\mathrm{CTE}$ is higher and stabilizes after few cycles to a negative value.

\section{Conclusions}

In conclusion we discussed the anomalous CTE observed in metal-matrix graphite composites. In such composites a vanishing or even negative CTE along the $\mathrm{z}$ axis is observed, when the graphite crystals are aligned within the composite. We examine the microscopic model recently suggested in Ref. [14] and find that is qualitatively predicts the 
changes in z-CTE. However, neutron scattering experiments find neither strain in the graphite fillers nor a strongly negative thermal expansion along the graphite $\mathrm{c}$ axis. We propose a more macroscopic view on the behavior of graphite within the metal. During cool-down after the sintering the graphite crystals were folded and crumbled (macroscopic strain). With the increase in temperature the crystallites are stretched out to their original shape, reducing their overall thickness and the length of the composite along z. Our reasoning is supported by the strong hysteresis observed in the first thermal cycles of the as-prepared composites.

\section{Acknowledgements}

We thank N. Tessier-Doyen (Univ. Limoges, France), Anton PJ Stampfl (Australian Nuclear Science and Technology Organisation) and Nils Stelzer (Aerospace \& Advanced Composites GmbH, Austria) for helpful discussions. V. O. wishes to acknowledge the Evonik Foundation for financial support. Further we acknowledge Benji Börner for the help with CTE measurements.

\section{Conflict of interests}

The authors declare that they have no conflict of interest.

\section{References}

1. Carlson RO, Glascock HH, Webster HF, Neugebauer CA (1984) Thermal expansion mismatch in electronic packaging. In: MRS Proc. Cambridge Univ Press, p 177

2. Zweben C (2005) Advanced electronic packaging materials. Adv Mater Process 163:33-37.

3. Korb G, Koráb J, Groboth G (1998) Thermal expansion behaviour of unidirectional carbon-fibrereinforced copper-matrix composites. Compos Part A 29:1563-1567. doi: http://dx.doi.org/10.1016/S1359-835X(98)00066-9

4. Sebo P, Stefanik P (2003) Copper matrix+-carbon fibre composites. Int J Mater Prod Technol 18:141159.

5. Ellis DL, McDanels DL (1993) Thermal conductivity and thermal expansion of graphite fiber-reinforced copper matrix composites. Metall Trans A 24:43-52. doi: 10.1007/BF02669601

6. Rawal S (2001) Metal-Matrix Composites for Space Applications. JOM J Miner Met Mater Soc 53:1417. doi: 10.1007/s11837-001-0139-z

7. Russell-Stevens M, Todd RI, Papakyriacou M (2006) Thermal expansion behaviour of ultra-high modulus carbon fibre reinforced magnesium composite during thermal cycling. J Mater Sci 41:62286236. doi: 10.1007/s10853-006-0318-y

8. Silvain J-F, Veillère A, Lu Y (2014) Copper-Carbon and Aluminum-Carbon Composites Fabricated by Powder Metallurgy Processes. J Phys Conf Ser 525:012015. doi: 10.1088/1742-6596/525/1/012015 
9. Yoshida K, Morigami H (2004) Thermal properties of diamond/copper composite material. Microelectron Reliab 44:303-308. doi: 10.1016/S0026-2714(03)00215-4

10. Boden A, Boerner B, Kusch P, et al (2014) Nanoplatelet size to control the alignment and thermal conductivity in copper-graphite composites. Nano Lett 14:3640-3644. doi: 10.1021/n1501411g

11. Oddone V, Boerner B, Reich S (2017) Composites of aluminum alloy and magnesium alloy with graphite showing low thermal expansion and high specific thermal conductivity. Sci Technol Adv Mater 18:180-186. doi: 10.1080/14686996.2017.1286222

12. Oddone V, Reich S (2017) Thermal properties of metal matrix composites with planar distribution of carbon fibres. Phys status solidi - Rapid Res Lett 1700090:1700090. doi: 10.1002/pssr.201700090

13. Prieto R, Molina JM, Narciso J, Louis E (2008) Fabrication and properties of graphite flakes/metal composites for thermal management applications. Scr Mater 59:11-14. doi:

10.1016/j.scriptamat.2008.02.026

14. Firkowska I, Boden A, Boerner B, Reich S (2015) The Origin of High Thermal Conductivity and Ultralow Thermal Expansion in Copper-Graphite Composites. Nano Lett 15:4745-4751. doi: 10.1021/acs.nanolett.5b01664

15. Chu K, Wang X hu, Li Y biao, et al (2018) Thermal properties of graphene/metal composites with aligned graphene. Mater Des 140:85-94. doi: 10.1016/j.matdes.2017.11.048

16. Hutsch T, Schubert T, Schmidt; J, et al (2010) Innovative Metal-Graphite Composites as Thermally Conducting Materials. In: Proc. Powder Metall. World Congr. Exhib. PM2010. pp 361-368

17. Hutsch T, Schubert T, Weissgaerber T, Kieback B (2012) Graphite metal composites with tailored physical properties. Emerg Mater Res 1:107-114. doi: 10.1680/emr.11.00021

18. Zhou C, Ji G, Chen Z, et al (2014) Fabrication, interface characterization and modeling of oriented graphite flakes/Si/Al composites for thermal management applications. Mater Des 63:719-728. doi: 10.1016/j.matdes.2014.07.009

19. Oddone V, Segl J, Prakasam M, et al (2018) Isotropic thermal expansion in anisotropic thermal management composites filled with carbon fibres and graphite. J Mater Sci 53:10910-10919. doi: $10.1007 / \mathrm{s} 10853-018-2373-6$

20. Wang X, Wang X, Liu M, et al (2018) Anisotropic thermal expansion coefficient of multilayer graphene reinforced copper matrix composites. J Alloys Compd 755:114-122. doi: 10.1016/j.jallcom.2018.04.325

21. Schapery RA (1968) Thermal expansion coefficients of composite materials based on energy principles. J Compos Mater 2:380-404.

22. Kerner EH (1956) The elastic and thermo-elastic properties of composite media. Proc Phys Soc Sect B 69:808. 
23. Turner PS (1942) The problem of thermal-expansion stresses in reinforced plastics. Natl Advis Committes Aeronaut 36:1-23.

24. McCullough RL (1985) Generalized combining rules for predicting transport properties of composite materials. Compos Sci Technol 22:3-21.

25. Nelson JB, Riley DP (1945) The thermal expansion of graphite from 15 c. to 800 c.: Part I. Experimental. Proc Phys Soc 57:477.

26. Blakslee OL, Proctor DG, Seldin EJ, et al (1970) Elastic constants of compression-annealed pyrolytic graphite. J Appl Phys 41:3373-3382. doi: 10.1063/1.1659428

27. Cobden R (1994) Aluminium: physical properties, characteristics and alloys. European Aluminium Association

28. (2007) Data Sheet: an Aluminium Alloy With the Strength of Steel (Alloy 7068). Advanced Metals International, Bedfordshire, United Kingdom

29. DeGarmo EP, Black JT, Kohser RA, Klamecki BE (1997) Materials and process in manufacturing. Prentice Hall

30. Briche G, Tessier-Doyen N, Huger M, Chotard T (2008) Investigation of the damage behaviour of refractory model materials at high temperature by combined pulse echography and acoustic emission techniques. J Eur Ceram Soc 28:2835-2843. doi: 10.1016/j.jeurceramsoc.2008.04.023 